\title{
Rheological properties of disintegrated sewage sludge
}

\author{
Pawet Wolski ${ }^{1, *}$ \\ ${ }^{1}$ Czestochowa University of Technology, Faculty of Infrastructure and Environment, Institute of \\ Environmental Engineering, ul. Brzeznicka 60a, 42-200 Czestochowa, Poland
}

\begin{abstract}
The rheology of the sludge provides information about the capacity and the flow, which in the case of project tasks for the hydraulic conveying installation is an important control parameter. Accurate knowledge of the rheological properties of sludge requires the designation of rheological models. Models single and multiparameter (Ostwald, Bingham, Herschel-Bulkley'a, and others) allow an approximation of flow curves, and the determination of the boundaries of the flow of modified sludge allows you to control the process compaction or are dewatered sludge undergoing flow. The aim of the study was to determine the rheological parameters and rheological models of sludge conditioned by physical methods before and after the process of anaerobic digestion. So far, studies have shown that the application of conditioning in the preparation of sewage sludge increases shear stress, viscosity as well as the limits of flow in relation to the untreated sludge. Offset yield point by the application of a conditioning agent is associated with decreased flowability tested sludge, which has also been observed by analyzing the structure of the prepared samples. Lowering the yield point, and thus the shear stress was recorded as a result of the fermentation test of disintegrated sludge.
\end{abstract}

\section{Introduction}

Rheology is the study of flow, dealing with the phenomena of deformation and flow caused by external mechanical stresses, occurring over a finite time [1]. Familiarizing with properties of bodies and the movement of some elements of a body with regards to the other is of essential importance to hydraulic transport. Determination of the models used for the description of bodies exposed to the effect of force can be used for its characterization e.g. after the process of conditioning or fermentation [2].

Rheological analysis of sewage sludge considered as multi-phase systems with flocculent structure reveals changes in their rheological parameters through the increase in dry matter content. Intervention in the structure of sludge through application of conditioning factors and exposing them to stabilization contributes to changes in the value of stress, viscosity and yield limits. Neglecting of these parameters may generate substantial design errors, thus leading to functional problems with the whole system of sludge treatment [3-5].

\footnotetext{
*Corresponding author: pwolski@is.pcz.czest.pl
} 
In the research on rheological properties, apart from determination of flow curves and viscosity, one should also develop rheological models which allow for approximation of flow curves $[6,7]$. Among common rheological models used for the description of flow curves is the Ostwald-de Waele power model:

$$
\tau=k \cdot(\gamma)^{n}
$$

where the constant $k\left[\mathrm{~Pa}^{*} \mathrm{~s}\right]$, termed consistency coefficient, and the exponent $n$, termed the yield exponent, are the rheological parameters determined empirically at a specific temperature. The coefficient $k$ is the measure of viscosity, which means that the higher the $k$ value the more viscous the fluid. Yield exponent $\mathrm{n}$ adopts values of $n<1$ (shear thinning), $n>1$ (shear thickening) and $n=1$ (Newtonian fluid).

In the Bingham model, for lower fluid stresses, fluids behave as plastic solid bodies, whereas flow is observed only after application of the shear stress $\tau 0$ :

$$
\tau=\tau_{o}+\eta_{p l} \bullet \gamma
$$

value of yield stress $\tau_{o}[\mathrm{~Pa}]$ and plastic viscosity $\eta_{p l}[\mathrm{~Pa} \bullet \mathrm{s}]$ are parameters that are also determined experimentally. In the case of the three-parameter model, e.g. the Herschel-Bulkley model, apart from the yield stress $\tau_{o}$, the constant $K$ is also used, similar to $\mathrm{n}$ :

$$
\tau=\tau_{o}+K \cdot(\gamma)^{n}
$$

Determination of the curves of flow and viscosity and the analysis of rheological models contributes to the development of precise knowledge about the fluids, which is directly connected with security of sending the fluids [8-10].

The aim of the study was to determine rheological parameters of sewage sludge after physical conditioning, followed by the stabilization process.

\section{Methodology}

The examinations concerned sewage sludge from the cellulose treatment plant with initial hydration of $98.4 \%$, whereas total solids (TS) was $1.6 \mathrm{~g} / \mathrm{dm}^{3}$. The sonication process was conducted under static conditions using the ultrasound field with intensity of $2.7 \mathrm{~W} / \mathrm{cm}^{2}$; $3.2 \mathrm{~W} / \mathrm{cm}^{2}$ and $3.8 \mathrm{~W} / \mathrm{cm}^{2}$. The initial power of the ultrasonic processor was $1500 \mathrm{~W}$, with vibration frequency of $20 \mathrm{kHz}$, and maximal wave length of $39.42 \mu \mathrm{m}$. Sonotrod emitting an ultrasonic field was placed under the surface of the modified sludge, $2 \mathrm{~cm}$ from the bottom of the beaker in which the sludge were conditioned. The volume of the sonicated sludge samples was $500 \mathrm{~cm}^{3}$, whereas the exposure time was $600 \mathrm{~s}$.

Pre-sonicated sludge were subjected to a fermentation process in parallel in the glass flasks with capacity of $0.5 \mathrm{dm}^{3}$ and in the lab-bioreactor with capacity of $7 \mathrm{dm}^{3}$ (in both cases the laboratory models of the fermentation chamber). The analysis concerned non-conditioned and non-fermented sludge, sludge after conditioning and fermentation for 5 and 10 days in glass flasks, and sludge after conditioning and fermentation for 25 days in the lab-bioreactor. The fermentation process, both in flasks and bioreactor, was carried out under mesophilic conditions $\left(37^{\circ} \mathrm{C}\right)$. In order to mix and maintain the set temperature, the flasks were placed on magnetic stirrers and inserted into a laboratory thermometer. In the bioreactor, the set temperature was maintained with the aid of heaters, while stirring was continued using a stirrer. Parameters and rheological models were determined for sewage 
sludge at the shear rate of $0-200 \mathrm{~s}^{-1}$ for the period of $120 \mathrm{~s}$, using the cylindrical rheometer RC20.

\section{Results}

Analysis of the results of the study revealed the effect of the conditioning factor (ultrasound field) and the process of stabilization conducted in the anaerobic environment on changes in shear stresses, viscosity and yield limit. Analysis of the values of the Ostwald model showed a reduction in viscosity, expressed by the consistency coefficient, with elongation of the fermentation time (see Fig. 1). This value was reduced from 0.143 Pas (non-conditioned and non-fermented sludge) to 0.028 Pas on the 10th day of fermentation. In the case of the bioreactor, consistency was 0.053 Pas. A five-time increase in viscosity was observed in the case of sludge exposed to the effect of the ultrasound field. In the model, the value of non-fermented sludge for the lowest ultrasound field intensity $\left(2.7 \mathrm{~W} / \mathrm{cm}^{2}\right)$ was 0.541 Pas and it continued to increase to 0.585 Pas for the highest field intensity $\left(3.8 \mathrm{~W} / \mathrm{cm}^{2}\right)$. The reduction in viscosity for all three values of the wave length was found after fermentation of the samples. The lowest consistency (0.076 Pas) was observed on the 10th day of fermentation for the sludge sonicated with ultrasound field with intensity of $3.8 \mathrm{~W} / \mathrm{cm}^{2}$. The yield exponent $n$ was increasing on each day of the fermentation process. For each tests, the exponent was below unity $(n<1)$, ranging from 0.38 to 0.63 .

The values obtained correlated with rheological parameters determined empirically (Fig. 2). The values of viscosity were also rising with elongation of the ultrasound field effect, whereas fermentation caused a reduction in the parameter studied.

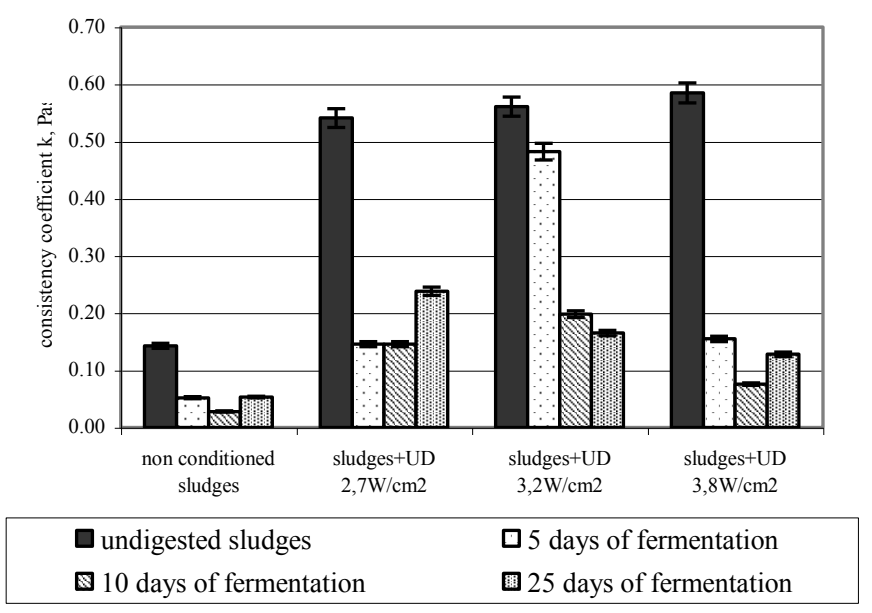

Fig. 1. The dependency of the consistency coefficient determined in the Ostwald model on ultrasound field intensity and fermentation time. 


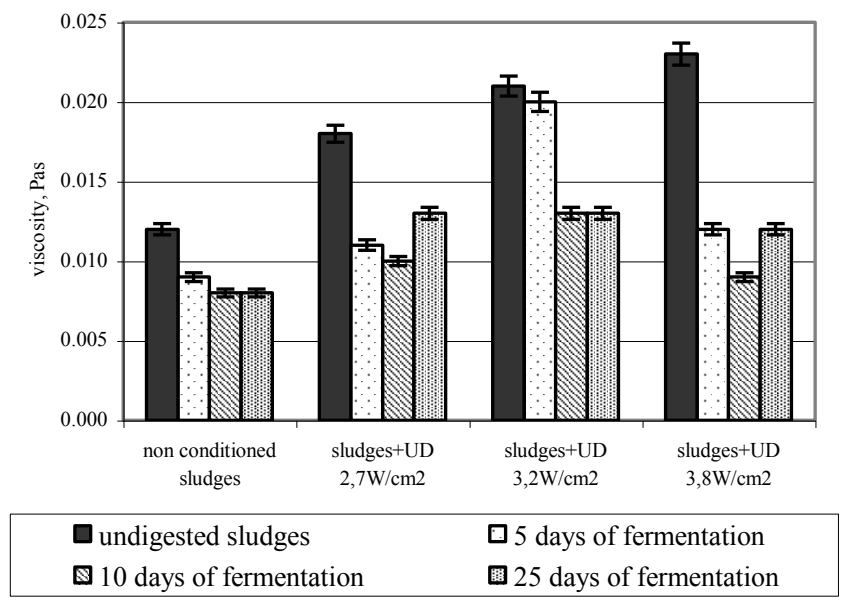

Fig. 2. The dependency of the empirically determined viscosity on ultrasound field intensity and fermentation time.

The analysis of the Bingham model revealed the effect changes in the conditioning factor and fermentation on rheological parameters (Fig. 3). The flow limit in the case of the non-conditioned sludge after fermentation was reduced on consecutive days of the process. This parameter was reduced for three times, from $0.466 \mathrm{~Pa}$ (non-fermented sludge) to 0.154 $\mathrm{Pa}$ (sludge on $10^{\text {th }}$ day of stabilization). Similar to viscosity, elongation of the yield stress was affected by the use of the energy of the ultrasound field. The most substantial effect of the shift in this rheological parameter was observed in the case of non-fermented sludge after exposure to the ultrasound field with intensity of $3.8 \mathrm{~W} / \mathrm{cm}^{2}$. A substantial reduction in the yield stress was found after exposure of the sewage sludge to fermentation. Yield stress was reducing for each ultrasound field wave length, with the lowest value $(0.276 \mathrm{~Pa})$ observed on the 10th day of fermentation after sonication with field intensity of $3.8 \mathrm{~W} / \mathrm{cm}^{2}$. The analogous pattern was found for the Herschel-Bulkley model (Fig. 4). The yield stress values were insignificantly lower compared to yield stress in the Bingham model.

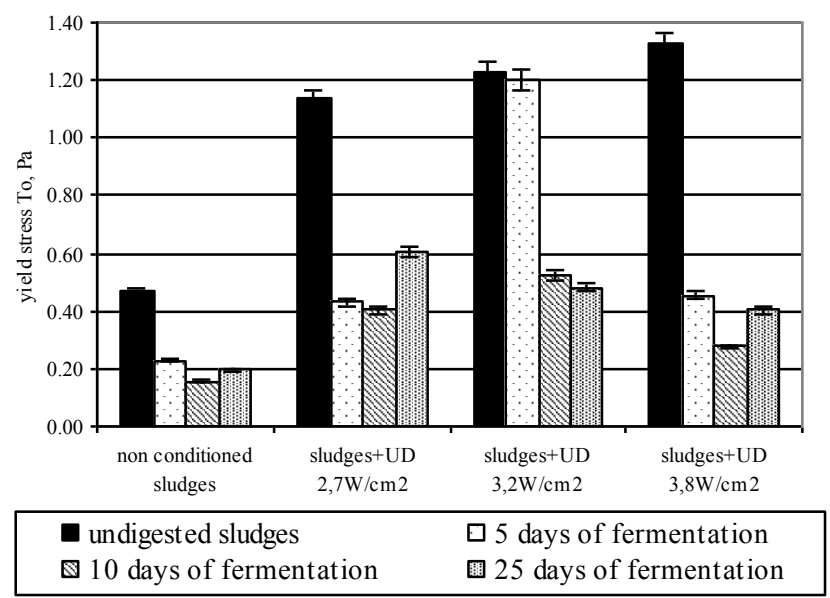

Fig. 3. The dependency of the yield stress determined in the Bingham model on ultrasound field intensity and fermentation time. 


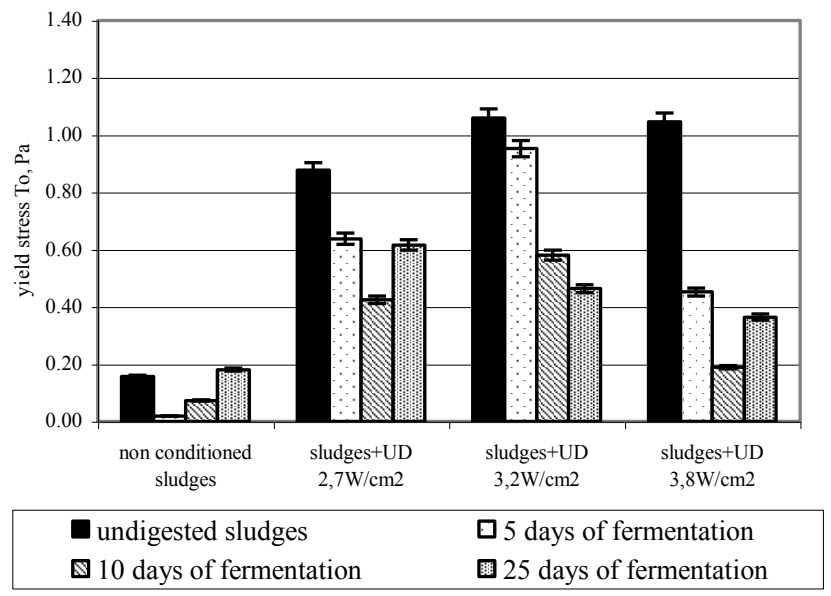

Fig. 4. The dependency of the yield stress determined in the Herschel-Bulkley model on ultrasound field intensity and fermentation time.

The yield stress values determined in the models were correlated with the values of yield stress determined empirically. Values of stresses in sewage sludge increased directly proportionally to the ultrasound field intensity, reaching the highest value $(4.616 \mathrm{~Pa})$ at the intensity of $3.8 \mathrm{~W} / \mathrm{cm}^{2}$ (Fig. 5). Similar to viscosity and yield stress, the use of fermentation led to a reduction in shear stress in sludge samples.

It is remarkable that TS of sewage sludge after conditioning with the ultrasound field and fermentation was changing. The increase in daily reduction in TS was observed on consecutive days of the stabilization process (see Fig. 6). However, the most noticeable reduction effect was found for sonicated sludge. On the $2^{5 \text { th }}$ day of fermentation, the decrease in TS of the sludge conditioned with the ultrasound field with intensity of $3.2 \mathrm{~W} / \mathrm{cm}^{2}$ was $2.26 \mathrm{~g} / \mathrm{dm}^{3}$, whereas this value for the exposure to the field intensity of $3.8 \mathrm{~W} / \mathrm{cm}^{2}$ was $4.69 \mathrm{~g} / \mathrm{dm}^{3}$.

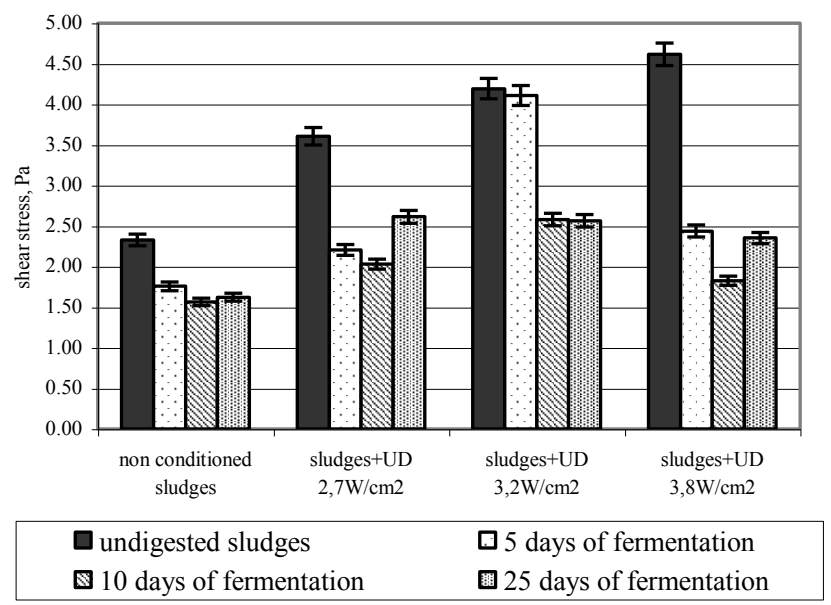

Fig. 5. The dependency of the empirically determined shear stresses on ultrasound field intensity and fermentation time. 


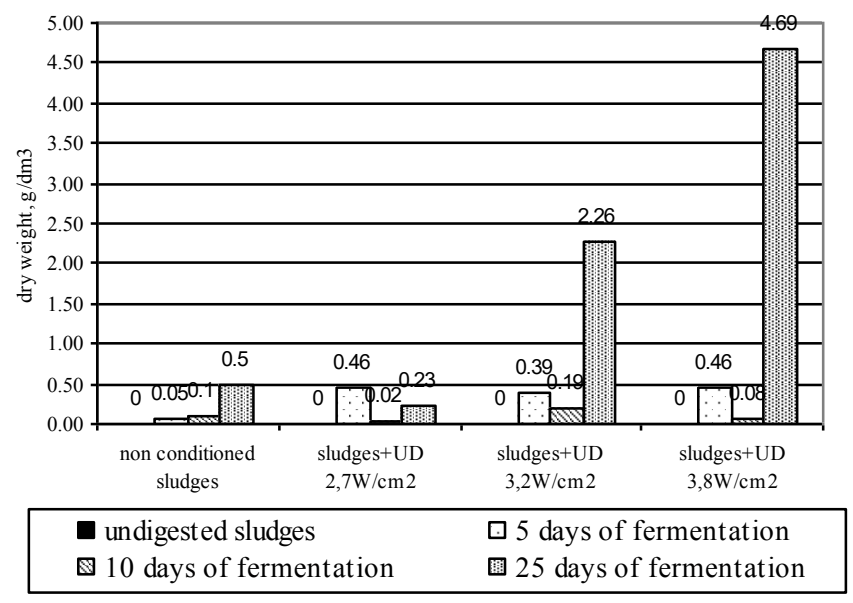

Fig. 6. The dependency of daily decrease in dry matter on ultrasound field intensity and fermentation time.

\section{Conclusions}

Knowledge of the properties and rheological parameters of fluids is essential to minimize calculation errors connected with their processing and hydraulic transport. It is also important to support dewatering and, more and more often, fermentation, through exposure of sewage sludge to physical conditioning. As observed based on the examinations, conditioning through sonication has an effect on changes in rheological parameters (viscosity, shear stress, yield stress). Fermentation also has a significant effect on hydraulic properties of sewage sludge.

The analysis of the results obtained in this study leads to the following conclusions:

- Consistency coefficient (which represents the measure of viscosity in the Ostwald model) and the empirically determined viscosity rose as ultrasound field intensity increased. The stabilization process led to the reduction in the value of the parameters discussed.

- Values of yield limit and stresses in the sewage sludge were increased after sonication. After the fermentation process, yield limit was reducing as stabilization time was elongating.

- The ultrasound field intensified the process of fermentation, which is reflected by the more substantial daily decrease in TS.

The research was funded by the project No. $B S-P B-401 / 303 / 12$

\section{References}

1. M.M. Sozański, E.S. Kempa, K. Grocholski, J. Bień, Water Sci. Technol. 36, 69-78 (1997)

2. R. Aranowski, J. Hupka, Ch. Jungnickel, Physicochem. Probl. Miner. Process 44, 13-22 (2010)

3. B. Fryźlewicz-Kozak, O. Długosz, Inż. Ap. Chem. 54, 31-32 (2015) (in Polish) 
4. B. Fryźlewicz-Kozak, J. Jamróz, M. Pachołek, Inż. Ap. Chem. 54, 33-35 (2015) (in Polish)

5. P. Travnicek, T. Vitez, P. Junga, E. Krcalova, J. Sevcikova, Pol. J. Environ. Stud. 1209-1212 (2013)

6. M. Ruiz-Hernando, G. Martinez-Elorza, J. Labanda, J. Lorens, Chem. Eng. J. 230, 102-110 (2013)

7. Y. Dong, Y. Wang, Acta Scientiae Circumstantiae, 678-682 (2012)

8. I. Zawieja, L. Wolny, Annual Set Environ. Protect. 13, 1719-1730 (2011)

9. F. Markis, J. Baudez, R. Parthasarathy, P. Slatter, N. Eshtiaghi, Chem. Eng. J. 253, 526-537 (2014)

10. L. Wolny, P. Wolski, I. Zawieja, Desalination 222, 1, 382-387 (2008) 